\title{
Health-related quality of life of children and adolescents after hematopoietic stem cell transplantationa
}

\author{
Yu Min Hwang ${ }^{1}$, Kyung-Sook Bang ${ }^{2}$ \\ ${ }^{1}$ Registered Nurse, Seoul National University Hospital, Seoul; ${ }^{2}$ Professor, College of Nursing, Research Institute of Nursing Science, Seoul National University, \\ Seoul, Korea
}

\begin{abstract}
Purpose: This study aimed to determine the level of health-related quality of life (HRQoL) of children and adolescents who received hematopoietic stem cell transplantation (HSCT) and to examine factors influencing HRQoL. Methods: This crosssectional descriptive study involved 85 participants aged 10 to 19 years who received treatment from 3 months to 5 years after HSCT. Symptom experiences, stress and coping, self-esteem, social support, and HRQoL were measured. Descriptive analysis, the independent $t$-test, one-way analysis of variance, Pearson correlation analysis, and stepwise multiple regression were used for data analysis. Results: The mean HRQoL score was 72.26 points out of 100 . HRQoL showed statistically significant correlations with symptom experiences, stress, self-esteem, social support, satisfaction with peer relationships, and perceived attentiveness of the medical team. The most influential predictors of HRQoL were symptom experiences $(\beta=-.51, p<.001)$ and satisfaction with peer relationships $(\beta=.32, p<.001)$. Conclusion: The experiences of different symptoms by children and adolescents who receive HSCT must be considered. In addition, nursing interventions, such as self-help meetings with peer groups, should be provided to improve their HRQoL.
\end{abstract}

Key words: Adolescent; Child; Hematopoietic stem cell transplantation; Quality of life

\section{Corresponding author Kyung-Sook Bang \\ https://orcid.org/0000-0001-9902-9716}

College of Nursing, Seoul National University,

103 Daehak-ro, Jongno-gu, Seoul 03080, Korea

TEL +82-2-740-8819 FAX +82-2-765-4103

E-MAIL ksbang@snu.ac.kr

*This article was adapted from a thesis by Yu Min Hwang in partial fulfillment of the requirements for the master's degree at Seoul National University.

*This study was supported by the research fund of Seoul Nurses Association in 2019.

Received Jul 18, 2020 Revised Aug 28, 2020 Accepted Sep 19, 2020 (a) This is an Open Access article distributed under the terms of the Creative Commons Attribution NonCommercial License (http://creativecommons.org/licenses/by-nc/4.0/) which permits unrestricted noncommercial use, distribution, and reproduction in any medium, provided the original work is properly cited.

\section{INTRODUCTION}

Hematopoietic stem cell transplantation (HSCT) restores bone marrow function after irradiation with high-dose anticancer drugs or radiation as a pretreatment to remove tumor cells and suppress immunity to prevent rejection of the transplanted cells. The outcomes of transplantation have been continuously improved through the diversification of pretreatment therapies, the use of new transplant sources, and drug development [1].

However, after HSCT, children with cancer experience side effects such as graft-versus-host disease, severe immune suppression, infertility, growth and developmental disorders, cataracts, recurrence, and secondary malignant tumors that occur during the long-term transplantation process. This often leads to physical, psychological, and social difficulties [2]. Since these problems are consequences of the effects of treatment, the concept of quality of life, which indicates how well the negative effects of treatment and survival are managed, has emerged as an important indicator [3].

Because health-related quality of life (HRQoL) is a subjective state of well-being felt in relation to one's internal and surrounding relationships, it varies according to individual expectations and values [4]. Therefore, children and adoles- 
cents who receive treatment during their corresponding developmental stages can assign different meanings to this experience than adults. Children and adolescents with cancer have physical problems (e.g., abnormal hormone secretion, developmental disorders, and physical sequelae) [5], psychosocial problems (e.g., depression, anxiety, and social immaturity), and emotional and social problems (e.g., low self-esteem and inferiority) [6]. These problems are complex and affect children and adolescents with cancer even years after the end of treatment [7]. In particular, people with cancer face the need to overcome treatment-related problems while simultaneously achieving normal developmental milestones. These experiences are therefore considered to be especially difficult for children and adolescents and require re-adaptation, which can lead to stress [8]. However, since prior studies on children and adolescents who have undergone HSCT have not actively included a broad variety of variables compared to people with cancer, research on the correlations of HRQoL and its influencing factors are needed.

Domestic research on children with cancer and their families has tended to include various age groups (e.g., 10-20 years of age). Moreover, in most studies, the developmental stage of the children are either not clearly classified or the classification criteria are applied in different ways by different researchers. In the current study, the term "children and adolescents" refers to individuals aged 10-19 years, including the minimum and maximum ages as reported in a previous study [9].

HRQoL can affect the overall life experiences of children and adolescents, such as their internal and external characteristics and social relationships. Therefore, this study aimed to investigate the factors related to HRQoL that have been affected by disease and treatment in children and adolescents who have undergone HSCT, and to examine the relationships among these factors.

Thus, the objectives of this study were as follows: 1) to compare HRQoL according to general characteristics; 2) to identify correlations among symptom experiences, stress, coping, self-esteem, social support, and HRQoL; and 3) to identify factors affecting HRQoL.

\section{METHODS}

\section{Study Design and Participants}

This descriptive correlational study was conducted to identify HRQoL-related factors in children and adolescents after HSCT. The participants of this study were children and adolescents who were undergoing outpatient follow-up after HSCT at a university hospital in Seoul, South Korea. Specifically, the inclusion criteria were as follows: (1) children and adolescents aged 10-19 years who underwent allogeneic or autologous HSCT and were receiving follow-up management from 3 months to 5 years after HSCT, (2) children and adolescents and their parents who understood the purpose and methods of this study and consented to participate in the study, and (3) children and adolescents who understood and were able to respond to the questionnaire and could communicate appropriately.

The sample size was determined using $G^{*}$ Power version 3.1.9 based on an effect size of .20, a significance level of .05, and a power of .80 , and the use of five predictive factors (symptom experiences, stress, coping, self-esteem, and social support) for multiple regression analysis. After calculation, the minimum required sample size was found to be 70 , and an intended sample of 84 was planned, taking into account with a $20 \%$ withdrawal rate. The final number of participants who answered the questionnaire of this study was 85 .

\section{Measurements}

\section{1) General characteristics}

The following general characteristics of the subjects were analyzed: sex, age, diagnosis, type of HSCT, time since HSCT, family composition, and enrollment in school. In addition, children's environment (i.e., family, friends, and medical personnel), were also considered as variables affecting HRQoL, and the questionnaire included questions about how much time they spent communicating with family members, their satisfaction with peer relationships, and the perceived attentiveness of the medical team.

\section{2) Symptom experiences}

Symptom experiences were measured using the tool developed by Larsen et al. [10], consisting of intensity, timing, distress, and quality, as revised by Kim [11]. Symptom experiences are perceived subjectively by the patient, and this variable is an observed index resulting from changes to normal function. This tool includes symptoms (nausea, vomiting, fever, chills, cough, pain, difficulty of breathing, fatigue, dry mouth, mouth ulcers, changes in taste, diarrhea, constipation, skin changes, loss of appetite, sleep disorders, activity disorders, depression, anxiety, concentration disorder, memory impairment, hair loss, sexual problems, appearance change, and eye problems) and one question on the patient's overall well-being (26 questions). This study used 24 questions, excluding the question related to sexual well-being, which is unlikely to be applicable to children and adolescents, and a duplicate question on overall well-being. This study analyzed how often (frequency), how severely (intensity), and how painful (painful) the symptoms were experienced in the last 
2-3 days. Cronbach's $\alpha$, as a measure of the reliability of the tool, was .81 at the time of development [10], .76 in the study by Kim [11], and .92 in this study.

\section{3) Stress and coping}

Stress was measured using a standardized stress visual analog scale developed by Cline et al. [12], which ranged from 0 to 10. Stress coping behavior was measured using the Korean-language version of the tool, which uses a 4-point scale and consists of 20 questions [13]. Cronbach's $\alpha$ for this tool was .81 in the study by Park and Chung [13] and .74 in this study.

\section{4) Self-esteem}

Self-esteem was measured using the tool translated by Lee and Won [14], based on the instrument created by Rosenberg. It consists of a total of 10 questions, each of which is measured on a 5 -point scale, with negative questions $(2,4,5$, and 10$)$ graded in reverse. Cronbach's $\alpha$ for this tool was .89 in the study by Lee and Won [14] and .90 in this study.

\section{5) Social support}

The Multidimensional Scale of Perceived Social Support developed by Zimet et al. [15] and translated by Hong and Park [16] was used. This tool measures the degree of support from family, friends, and special people perceived by the subjects. In this study, the special people were medical personnel (doctors and nurses). This tool consists of 12 questions in three areas: family support (four items), friend support (four items), and medical support (four items). The responses to each question are on a 7-point scale. Cronbach's $\alpha$ was .88 at the time of development [15], .92 in the study by Hong and Park [16], and .88 in this study.

\section{6) Health-related quality of life}

The Korean version of the Pediatric Quality of life Inventory (PedsQLTM) 4.0 self-reporting tool, developed by Varni et al. [17] and validated by Kook and Varni [18], was used. The PedsQLTM 4.0 is suitable for the developmental stages including 2-18 years of age, and self-reporting is available for 5-18 years of age. This tool consists of questions related to physical functioning (eight questions), emotional functioning (five questions), social functioning (five questions), and school functioning (five questions). The options for each item range from "nothing at all (0 points)" to "almost always (4 points)". Next, the original score for each item is converted to a score ranging from $0-100$ points by the following conversion: 0 points $=100,1$ point $=75,2$ points $=50,3$ points $=25$, and 4 points $=0$. Cronbach's $\alpha$ for this tool was .90 in the study by Kook and Varni [18] and .93 in this study.

\section{Data Collection Procedure}

The study was approved by the Institutional Review Board of the university hospital in Seoul with which the principal investigator was affiliated (approval no. 1910-190-1078). To recruit study participants, the researcher reviewed children and adolescents with cancer who visited the pediatric oncology outpatient clinic and met the inclusion criteria. A consent form was obtained from each patient's caregiver, who indicated that they understood the purpose and methods of the study and provided consent that the child could participate in the study. The children or adolescents then received an explanation of the study and signed an assent form indicating that they would participate in the study, after which the questionnaire survey was conducted.

In addition, the researcher conducted surveys in the outpatient waiting room during the outpatient waiting time. The completed questionnaires were immediately collected. Filling out the questionnaire took about 15-20 minutes. The data collection period of this study was from February to April 2020. A total of 87 copies of the questionnaire were distributed, and 85 copies were used as analytical data, excluding two copies with unanswered questions or unreasonable responses.

\section{Data Analysis}

SPSS version 26 (IBM Corp., Armonk, NY, USA) was used to analyze the collected data. The subject's general characteristics and measurement variables (symptom experiences, stress, coping, self-esteem, social support, and HRQoL) were analyzed using descriptive statistics. Multivariate normality of the sample was determined, and the mean, deviation, skewness, kurtosis, tolerance, and variance inflation factor (VIF) were determined. The independent-sample t-test and one-way analysis of variance were used to analyze differences in HRQoL according to participants' general characteristics. Pearson correlation analysis was performed to analyze the correlations between symptom experiences, stress, coping, self-esteem, social support, and HRQoL. Using the variables that showed significant correlations as predictors, stepwise multiple regression analysis was performed to determine the relative influence of predictors on HRQoL.

\section{RESULTS}

\section{General Characteristics}

There were 50 males (58.8\%) and 35 females (41.2\%) in this study. The average age of the subjects was 15.3 years. Twenty children and adolescents $(23.5 \%)$ had acute lymphocytic leu- 
kemia, 14 children and adolescents $(16.5 \%)$ had acute myeloid leukemia, and 14 children and adolescents (16.5\%) had non-malignant diseases. The types of HSCT included autologous HSCT in 33 participants (38.8\%) and allogeneic HSCT in 52 participants $(61.2 \%)$. The time since HSCT for most participants $(50.6 \%)$ was 1 year to less than 3 years. Most of them had family members $(83.5 \%)$ including parents and siblings. Forty-six participants (54.1\%) had returned to school (Table 1).

Table 1. General Characteristics of the Participants $(N=85)$

\begin{tabular}{llc}
\hline Variables & Categories & $\mathrm{n}(\%)$ \\
\hline Sex & Male & $50(58.8)$ \\
& Female & $35(41.2)$ \\
Age (year) & $10-12$ & $16(18.8)$ \\
& $13-15$ & $29(34.1)$ \\
& $16-19$ & $40(47.1)$ \\
Diagnosis & ALL & $20(23.5)$ \\
& AML & $14(16.5)$ \\
& Non-malignancy & $14(16.5)$ \\
& Lymphoma & $12(14.1)$ \\
& Osteosarcoma & $10(11.7)$ \\
& Ewing sarcoma & $6(7.1)$ \\
Type of HSCT & Others & $9(10.6)$ \\
& Autologous & $33(38.8)$ \\
Time since HSCT & Allogeneic & $52(61.2)$ \\
& $\geq 3$ months \& <1 year & $13(15.3)$ \\
& $\geq 1$ year \& <3 years & $43(50.6)$ \\
& $\geq 3$ years \& <5 years & $29(34.1)$ \\
Family members & Parents and siblings & $71(83.5)$ \\
& Grandparents, parents, & $4(4.7)$ \\
& and siblings & $10(11.8)$ \\
& Others & $46(54.1)$ \\
& Yes & $39(45.9)$ \\
\hline Nohool enrollment & No & \\
& & \\
& &
\end{tabular}

ALL, acute lymphoblastic leukemia; AML, acute myeloid leukemia; HSCT, hematopoietic stem cell transplantation.

\section{Descriptive Statistics of Research Variables}

In this study, the average level of symptom experiences was 58.95 points out of 96 , the average level of stress was 4.01 points out of 10 , and the score for stress coping strategy was 41.22 points out of 80 . The average level of self-esteem was 34.96 points out of 50 and that of social support was 63.24 points out of 84 . The average amount of time spent communicating with family was 2.31 hours out of 8 . The average level of satisfaction with peer relationships was 7.36 points out of 10. When visiting the hospital, the average level of perceived attentiveness of the medical team was 8.54 points out of 10 . The mean total HRQoL was 72.26 points out of 100 , which was higher than the median value of the tool. The scores for HRQoL sub-items were as follows, in descending order: social functioning (average, 80.94 points), emotional functioning (average, 73.59 points), physical functioning (average, 69.41 points), and school functioning (average, 66.82 points) (Table 2).

Table 2. Research Variables of Participants $(N=85)$

\begin{tabular}{lcc}
\hline Variables & $\mathrm{M} \pm \mathrm{SD}$ & Range \\
\hline Symptom experiences & $58.95 \pm 16.03$ & $24-96$ \\
Stress & $4.01(2.69)$ & $0-10$ \\
Coping strategy & $41.22(7.04)$ & $20-80$ \\
Self-esteem & $34.96(7.46)$ & $10-50$ \\
$\quad \begin{array}{l}\text { Social support } \\
\quad \text { Time spent communicating }\end{array}$ & $63.24(12.24)$ & $12-84$ \\
$\quad$ with family & & $0-8$ \\
$\quad$ Satisfaction with peer & $7.36(2.36)$ & $1-10$ \\
$\quad$ relationships & & \\
$\quad$ Perceived attentiveness of the & $8.54(1.60)$ & $1-10$ \\
$\quad$ medical team & & \\
Health-related quality of life & $72.26(19.56)$ & $0-100$ \\
$\quad \begin{array}{l}\text { Physical functioning } \\
\text { Emotional functioning }\end{array}$ & $69.41(26.86)$ & \\
$\quad \begin{array}{l}\text { Social functioning } \\
\text { School functioning }\end{array}$ & $73.59(23.68)$ & \\
\hline
\end{tabular}

\section{Comparison of Health-related Quality of Life Accord- ing to General Characteristics}

No significant differences in HRQoL were found according to gender, age, diagnosis, type of HSCT, time since HSCT, family structure, and school enrollment (Table 3).

\section{Correlations of Variables}

The results of analyzing the correlations among measurement variables in this study are as follows (Table 4). HRQoL, which was the dependent variable of this study, showed a statistically significant negative correlation with symptom experiences $(\mathrm{r}=-.58, p<.001)$ and stress $(\mathrm{r}=-.39, p<.001)$. In addition, HRQoL had statistically significant positive correlations with self-esteem $(\mathrm{r}=.45, p<.001)$, social support $(\mathrm{r}=.24, p=.027)$, satisfaction with peer relationships $(\mathrm{r}=.44, p<.001)$, and perceived attentiveness of the medical team $(\mathrm{r}=.27, p=.014)$.

In addition, symptom experiences demonstrated a significant positive correlation with stress $(\mathrm{r}=.38, p<.001)$ and significant negative correlations with self-esteem $(\mathrm{r}=-.39, p<$ $.001)$ and satisfaction with peer relationships $(r=-.25, p=.021)$. 
Table 3. Health-related Quality of Life by Participants' Characteristics $(N=85)$

\begin{tabular}{|c|c|c|c|c|c|}
\hline Variables & Categories & $\mathrm{n}(\%)$ & $\mathrm{M} \pm \mathrm{SD}$ & $\mathrm{t}$ or $\mathrm{F}$ & $p$ \\
\hline Sex & $\begin{array}{l}\text { Male } \\
\text { Female }\end{array}$ & $\begin{array}{l}50(58.8) \\
35(41.2)\end{array}$ & $\begin{array}{l}71.76 \pm 22.20 \\
70.60 \pm 18.29\end{array}$ & 0.25 & .800 \\
\hline Age (year) & $\begin{array}{l}10-12 \\
13-15 \\
16-19\end{array}$ & $\begin{array}{l}16(18.8) \\
29(34.1) \\
40(47.1)\end{array}$ & $\begin{array}{l}76.19 \pm 21.05 \\
72.93 \pm 18.36 \\
68.13 \pm 21.84\end{array}$ & 1.02 & .365 \\
\hline Diagnosis & $\begin{array}{l}\text { ALL } \\
\text { AML } \\
\text { Non-malignancy } \\
\text { Lymphoma } \\
\text { Osteosarcoma } \\
\text { Ewing sarcoma } \\
\text { Others }\end{array}$ & $\begin{array}{c}20(23.5) \\
14(16.5) \\
14(16.5) \\
12(14.1) \\
10(11.7) \\
6(7.1) \\
9(10.6)\end{array}$ & $\begin{array}{l}66.45 \pm 21.01 \\
73.36 \pm 25.63 \\
73.36 \pm 22.52 \\
76.92 \pm 17.68 \\
68.50 \pm 10.77 \\
70.17 \pm 22.60 \\
71.89 \pm 22.18\end{array}$ & 0.40 & .878 \\
\hline Type of HSCT & $\begin{array}{l}\text { Autologous } \\
\text { Allogeneic }\end{array}$ & $\begin{array}{l}33(38.8) \\
52(61.2)\end{array}$ & $\begin{array}{l}73.67 \pm 17.41 \\
69.77 \pm 22.38\end{array}$ & 0.85 & .398 \\
\hline Time since HSCT & $\begin{array}{l}\geq 3 \text { months } \&<1 \text { year } \\
\geq 1 \text { year } \&<3 \text { years } \\
\geq 3 \text { years } \&<5 \text { years }\end{array}$ & $\begin{array}{l}13(15.3) \\
43(50.6) \\
29(34.1)\end{array}$ & $\begin{array}{l}71.92 \pm 15.11 \\
67.65 \pm 23.73 \\
76.38 \pm 16.73\end{array}$ & 1.59 & .211 \\
\hline Family members & $\begin{array}{l}\text { Parents and siblings } \\
\text { Grandparents, parents, and siblings } \\
\text { Others }\end{array}$ & $\begin{aligned} 71 & (83.5) \\
4 & (4.7) \\
10 & (11.8)\end{aligned}$ & $\begin{array}{l}71.58 \pm 19.88 \\
83.00 \pm 9.42 \\
64.50 \pm 27.09\end{array}$ & 1.21 & .305 \\
\hline School enrollment & $\begin{array}{l}\text { Yes } \\
\text { No }\end{array}$ & $\begin{array}{l}46(54.1) \\
39(45.9)\end{array}$ & $\begin{array}{l}74.83 \pm 16.76 \\
67.10 \pm 23.87\end{array}$ & 1.70 & .094 \\
\hline
\end{tabular}

ALL, acute lymphoblastic leukemia; AML, acute myeloid leukemia; HSCT, hematopoietic stem cell transplantation.

Table 4. Correlations among the Major Variables $(N=85)$

\begin{tabular}{|c|c|c|c|c|c|c|c|c|c|}
\hline \multirow{2}{*}{ Variables } & 1 & 2 & 3 & 4 & 5 & 6 & 7 & 8 & 9 \\
\hline & $\mathrm{r}(p)$ & $\mathrm{r}(p)$ & $\mathrm{r}(p)$ & $\mathrm{r}(p)$ & $r(p)$ & $\mathrm{r}(p)$ & $\mathrm{r}(p)$ & $\mathrm{r}(p)$ & $\mathrm{r}(p)$ \\
\hline 1. Symptom experiences & 1 & & & & & & & & \\
\hline 2. Stress & $\begin{array}{c}.38 \\
(<.001)\end{array}$ & 1 & & & & & & & \\
\hline 3. Coping strategy & $\begin{array}{l}.17 \\
(.125)\end{array}$ & $\begin{array}{l}.16 \\
(.151)\end{array}$ & 1 & & & & & & \\
\hline 4. Self-esteem & $\begin{array}{c}-.39 \\
(<.001)\end{array}$ & $\begin{array}{c}-.42 \\
(<.001)\end{array}$ & $\begin{array}{l}-.01 \\
(.965)\end{array}$ & 1 & & & & & \\
\hline 5. Social support & $\begin{array}{l}-.16 \\
(.143)\end{array}$ & $\begin{array}{l}-.20 \\
(.065)\end{array}$ & $\begin{array}{c}.10 \\
(.372)\end{array}$ & $\begin{array}{l}.24 \\
(.028)\end{array}$ & 1 & & & & \\
\hline $\begin{array}{l}\text { 6. Time spent communicating } \\
\text { with family }\end{array}$ & $\begin{array}{l}-.12 \\
(.274)\end{array}$ & $\begin{array}{l}-.20 \\
(.072)\end{array}$ & $\begin{array}{c}.04 \\
(.728)\end{array}$ & $\begin{array}{c}.22 \\
(.048)\end{array}$ & $\begin{array}{l}-.02 \\
(.885)\end{array}$ & 1 & & & \\
\hline $\begin{array}{l}\text { 7. Satisfaction with peer } \\
\text { relationships }\end{array}$ & $\begin{array}{l}-.25 \\
(.021)\end{array}$ & $\begin{array}{l}-.31 \\
(.004)\end{array}$ & $\begin{array}{c}.05 \\
(.623)\end{array}$ & $\begin{array}{c}.53 \\
(<.001)\end{array}$ & $\begin{array}{c}.39 \\
(<.001)\end{array}$ & $\begin{array}{l}.08 \\
(.487)\end{array}$ & 1 & & \\
\hline $\begin{array}{l}\text { 8. Perceived attentiveness of } \\
\text { the medical team }\end{array}$ & $\begin{array}{l}-.09 \\
(.427)\end{array}$ & $\begin{array}{l}-.24 \\
(.029)\end{array}$ & $\begin{array}{c}.12 \\
(.268)\end{array}$ & $\begin{array}{c}.22 \\
(.049)\end{array}$ & $\begin{array}{c}.34 \\
(.002)\end{array}$ & $\begin{array}{l}-.03 \\
(.760)\end{array}$ & $\begin{array}{c}.46 \\
(<.001)\end{array}$ & 1 & \\
\hline 9. HRQoL & $\begin{array}{c}-.58 \\
(<.001)\end{array}$ & $\begin{array}{c}-.39 \\
(<.001)\end{array}$ & $\begin{array}{l}-.09 \\
(.425)\end{array}$ & $\begin{array}{c}.45 \\
(<.001)\end{array}$ & $\begin{array}{c}.24 \\
(.027)\end{array}$ & $\begin{array}{c}.10 \\
(.376)\end{array}$ & $\begin{array}{c}.44 \\
(<.001)\end{array}$ & $\begin{array}{c}.27 \\
(.014)\end{array}$ & 1 \\
\hline
\end{tabular}

HRQoL, health-related quality of life. 
Statistically significant negative correlations were found between stress and self-esteem $(\mathrm{r}=-.42, p<.001)$, satisfaction with peer relationships $(\mathrm{r}=-.31, p=.004)$, and perceived attentiveness of the medical team $(\mathrm{r}=-.24, p=.029)$.

Meanwhile, perceived attentiveness of the medical team had statistically significant positive correlations with self-esteem $(\mathrm{r}=.22, p=.049)$, social support $(\mathrm{r}=.34, p=.002)$, and satisfaction with peer relationships $(\mathrm{r}=.46, p<.001)$ (Table 4$)$.

\section{Factors Affecting Health-related Quality of Life}

In this study, symptom experiences, stress, self-esteem, social support, satisfaction with peer relationships, and perceived attentiveness of the medical team showed significant correlations with HRQoL in children and adolescents who received HSCT. Stepwise multiple regression analysis was used to identify meaningful predictors. First, the Durbin-Watson statistic was used to test the assumptions of the regression analysis, and it was confirmed that the residual assumptions of equal variance and normal distribution were satisfied. Next, multi-collinearity was tested using tolerance and the VIF. Because the tolerance limit was $\leq 0.1$ and the VIF values were not $>10$, all variables had no problem with multi-collinearity.

In the regression model, symptom experiences were a significant predictor in the first step, with an explanatory power of $34 \%(\mathrm{~F}=42.81, p<.001)$. The regression model established in this study found to be statistically appropriate for HRQoL in the second step $(\mathrm{F}=31.62, p<.001)$, and the explanatory power of the entire model was $43 \%$. The most influential predictor was symptom experiences $(\beta=-.51, p<.001)$, followed by satisfaction with peer relationships $(\beta=.32, p<.001)$ (Table 5).

\section{DISCUSSION}

This study determined the level of HRQoL in children and adolescents who received HSCT and analyzed the influence of related factors. This information will help nurses provide appropriate nursing interventions to assist children and adoles- cents in adapting to changes in their life after transplantation and overcoming related crises.

In this study, the mean score of HRQoL was 72.26 points out of 100, which is similar to the moderate level reported in another study using the same tool, PedsQLTM 4.0 [19]. Compared with a previous study [20] that measured HRQoL by dividing children with leukemia into two groups according to whether they underwent HSCT, the participants of this study had a similar HRQoL to the transplanted group, but significantly lower HRQoL than the non-transplanted group. In addition, a prior study on the HRQoL of children with cancer found that children and adolescents receiving HSCT had lower HRQoL than children with cancer in general [21].

In this study, the physical functioning sub-domain of HRQoL had a score of 69.41 out of 100 , which was one of the lowest after school functioning (which had a score of 66.82 out of 100). In addition, symptom experiences and HRQoL showed the strongest negative correlation, and symptom experiences were found to be the most significant predictor of HRQoL. It is difficult to directly compare these results with previous studies because there has been no study on the symptoms of children and adolescents who have undergone HSCT. Nonetheless, the findings of this study are similar to those of a previous study reporting that the transplant group experienced more sequelae than the non-transplanted group [22], and that physical sequelae have different consequences on quality of life according to the disease characteristics [23].

Indeed, many children with childhood cancer experience physical problems that affect their social participation even after the completion of treatment, which is a barrier to their performance in roles such as completion of their education and employment. As such, symptom experiences have an important effect on HRQoL. Therefore, it is necessary to actively listen to patients' symptom experiences and to interact with them regularly using therapeutic communication. In addition, it is important to assess nursing problems starting at the beginning of treatment and to develop appropriate nursing interventions.

Table 5. Factors Influencing Health-related Quality of Life $(N=85)$

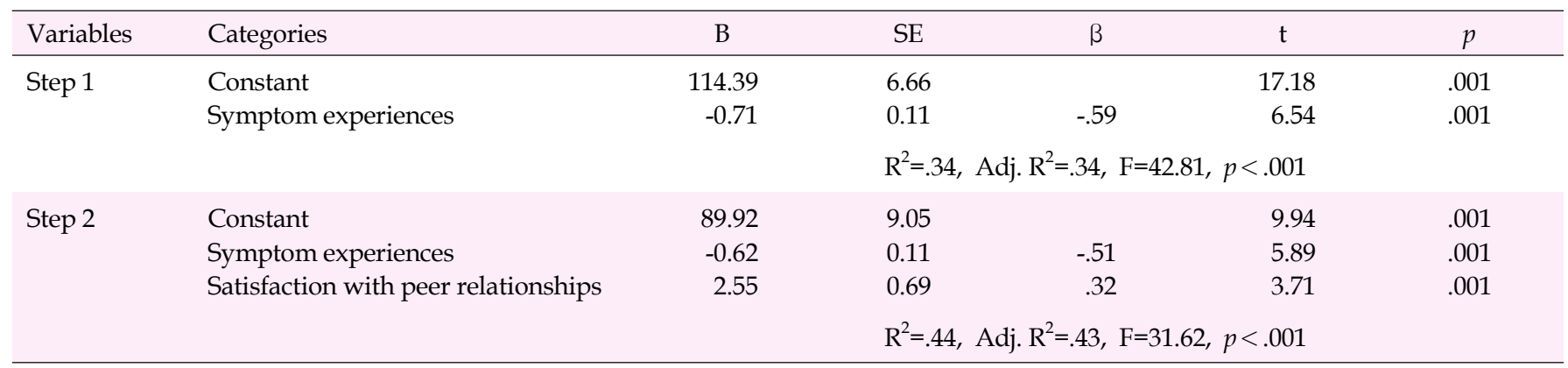


In this study, social functioning was the sub-domain of HRQoL with the highest mean score (80.94 out of 100). In addition, satisfaction with peer relationships had a positive correlation with HRQoL and was the most significant predictor for HRQoL after symptom experiences. Considering that a previous study also found that peer relationships were a major variable affecting adolescents' quality of life [24], the results of this study indicate that peer relationships were important for participants, in accordance with their developmental characteristics. Children and adolescents who have undergone HSCT are expected to be interested in peer relationships starting at the time of diagnosis. Regular evaluations are necessary to ensure that peer relationships can continue during the treatment period, and related nursing interventions (e.g., self-help meetings with peer groups) should be carried out.

Regarding school functioning, even though children and adolescents undergoing HSCT do not attend school, they continue their academic progress by various methods such as attending school at a children's hospital and video lectures. Therefore, participants may have had a high level of school functioning, a sub-area of HRQoL, regardless of whether they were enrolled in school. Although the HRQoL of children and adolescents attending school in the present study was higher than that of children and adolescents who did not attend school, this difference was not significant.

In contrast, positive self-esteem is an important personal resource for children to overcome their difficult situations by recognizing their strengths and weaknesses, realizing their own capabilities, and making independent decisions when challenges come. In light of this, even in children with cancer, self-esteem can be considered a major variable affecting adaptation despite the difficulties caused by cancer diagnosis or treatment [25]. In this study, higher self-esteem was associated with higher HRQoL, but when several factors were considered together, self-esteem did not seem to have a significant relationship with HRQoL. However, it is necessary to refer to previous studies indicating that adolescents with hematologic tumors show initiative and reorganization, which enable their ego not to be affected negatively because of the crisis of the life-threatening disease [26]. Children and adolescents have a strong desire for identification with their peers and a sense of belonging to the group. They should continue to develop their self-esteem and seek out ongoing, holistic interventions to improve their HRQoL.

This study found a statistically significant negative correlation between stress and HRQoL; similarly, a previous study on children and adolescent cancer survivors found a positive correlation between high stress symptoms and low HRQoL [27]. In children and adolescents with cancer, the treatment process and visits to hospitals that continue after treatment are a major source of stress. These may not only become bad memories during the growth process, but can also act as a negative factor impacting the overall quality of life of children and adolescents. Therefore, there is a need for an intervention program that can help children and adolescents find and resolve the difficulties that they experience in reducing stress and returning to daily life after treatment.

At the time of diagnosis, medical personnel are in a position to provide advice on improving existing social resources and health-related issues [28]. In this study, higher scores for perceived attentiveness of the medical team were associated with higher HRQOL and easier return to daily life. The results of a previous study also indicated that perceived attentiveness of the medical team plays an important role in the recovery of children with cancer. Children and adolescents are minors, and they are often treated under their parents' guidance, so the parents often decide on overall treatment. However, the medical team needs to provide disease-related information to children throughout the entire course of treatment, and should discuss possible problems with the children and adolescents.

In this study, social support did not seem to be a significant predictor of HRQoL, although it exhibited a significant correlation with HRQoL. In previous studies of adolescents with chronic diseases, receiving more support from family, friends, and healthcare providers was associated with higher HRQoL $[16,29]$. Therefore, we should consider ways to provide more practical social support to children and adolescents who undergo hematopoietic stem cell transplantation.

The limitations of this study are as follows. Comparing our results with those of previous studies was difficult because most of the existing studies on HRQoL were conducted on children or adults with cancer, not those who underwent HSCT. In addition, because data were collected by convenience sampling of children and adolescents who underwent HSCT at a university hospital, it is necessary to be cautious in generalizing the results of this study to all children and adolescents receiving HSCT.

Despite these limitations, it is significant that HRQoL was measured among children and adolescents who underwent HSCT, who have been difficult to recruit and have been insufficiently studied. In addition, an important contribution of this study is that it was possible to confirm the directions of nursing interventions required for future children and adolescents undergoing HSCT.

\section{CONCLUSION}

This study was conducted to identify the factors influencing HRQoL after HSCT in children and adolescents. Statistically significant correlations were found between HRQoL and symp- 
tom experiences, stress, self-esteem, social support, satisfaction with peer relationships, and perceived attentiveness of the medical team. The most important factors for the HRQoL of children and adolescents who underwent HSCT were symptom experiences and satisfaction with peer relationships.

In light of these findings, the HRQoL of children and adolescents who undergo HSCT could be further improved by providing ongoing, regular nursing interventions that take into account the characteristics of their developmental stages from the initial stage to the end of treatment.

\section{Conflict of interest}

No existing or potential conflict of interest relevant to this article was reported.

\section{Data availability}

Please contact the corresponding author for data availability.

\section{REFERENCES}

1. Gratwohl A, Baldomero H, Aljurf M, Pasquini MC, Bouzas LF, Yoshimi A, et al. Hematopoietic stem cell transplantation: A global perspective. Journal of American Medical Association. 2010;303(16): 1617-1624. https://doi.org/10.1001/jama.2010.491

2. Grant M, Cooke L, Williams AC, Bhatia S, Popplewell L, Uman G, et al. Functional status and health-related quality of life among allogeneic transplant patients at hospital discharge: A comparison of sociodemographic, disease, and treatment characteristics. Supportive Care in Cancer. 2012;20(11):2697-2704.

https://doi.org/10.1007/s00520-012-1389-8

3. Kiss TL, Abdolell M, Jamal N, Minden MD, Lipton JH, Messner HA. Long term medical outcomes and quality of life assessment of patients with chronic myeloid leukemia followed at least 10 years after allogeneic bone marrow transplantation. Journal of Clinical Oncology. 2002;20(9):2334-2343.

https://doi.org/10.1200/JCO.2002.06.077

4. Kim SY, Shim JY, Won JW, Seon WS, Park HK, Lee JK. The development of Korean health related quality of life scale (KQOLS). Journal of the Korean Academy of Family Medicine. 2000;21(3): 382-394. https://ir.ymlib.yonsei.ac.kr/handle/22282913/171948

5. Bhatia S, Landier W. Evaluating survivors of pediatric cancer. Cancer Journal. 2005;11(4):340-354.

https://doi.org/10.1097/00130404-200507000-00010

6. Oh KS, Sim MK, Son SY. Health problems and psychosocial adaptation of children with cancer. Journal of Korean Academy of Nursing. 2003;33(2):293-300.

7. Kazak AE, Alderfer M, Rourke MT, Simms S, Streisand R, Grossman JR. Post-traumatic stress disorder (PTSD) and posttraumatic stress symptoms (PTSS) in families of adolescent childhood cancer survivors. Journal of Pediatric Psychology. 2004;29(3):211-219. https://doi.org/10.1093/jpepsy/jsh022

8. Woodgate RL. A different way of being: Adolescent's experiences with cancer. Cancer Nursing. 2005;28(1):8-15.

https://doi.org/10.1097/00002820-200501000-00002

9. Cho HH, Yoon JW. Trends in research on children with cancer and their families in Korea. Journal of Korean Academy of Child Health Nursing. 2010;16(1):73-83.

https://doi.org/10.4094/jkachn.2010.16.1.73

10. Larsen J, Nordstrom G, Bjorkstrand B, Ljungman P, Gardulf A. Symptom distress, functional status and health related quality of life before high dose chemotherapy with stem cell transplantation. European Journal of Cancer Care. 2003;12(1):71-80. https://doi.org/10.1046/j.1365-2354.2003.00315.x

11. Kim KJ. Differences of symptom experiences according to gender and stage in hematopoietic stem cell transplant process [master's thesis]. Seoul: Yonsei University; 2004. p. 1-101.

12. Cline ME, Herman J, Shaw ER, Morton RD. Standardization of the visual analogue scale. Nursing Research. 1992;41(6):378-380. https://doi.org/10.1097/00006199-199211000-00013

13. Park JA, Chung MJ. Relationships between strategies for coping with stress and behavior problem in school-age children. Korean Journal of Child Studies. 2001;22(3):107-122.

14. Lee HJ, Won HT. Self-concepts and paranoid tendency. Seoul National University Research Institute of Psychology and Sciences. 1995;4(2):15-29.

15. Zimet GD, Dahlem NW, Zimet SG, Farley GK. The multidimensional scale of perceived social support. Journal of Personality Assessment. 1988;52(1):30-41. https://doi.org/10.1207/s15327752jpa5201_2

16. Hong SS, Park HR. Predictors of resilience in adolescents with leukemia. Journal of Korean Academy of Nursing. 2015;45(4):595-603. https://doi.org/10.4040/jkan.2015.45.4.595

17. Varni JW, Seid M, Kurtin PS. PedsQL 4.0TM: Reliability and validity of the Pediatric Quality of Life Inventory TM Version 4.0 Generic Core Scales in healthy and patient populations. Medical Care. 2001;39(8):800-812. https://doi.org/10.1097/00005650-200108000-00006

18. Kook SH, Varni JW. Validation of the Korean version of the pediatric quality of life inventory 4.0 (PedsQL) generic core scales in school children and adolescents using the Rasch model. Health and Quality of Life Outcomes. 2008;41:6-41. https://doi.org/10.1186/1477-7525-6-41

19. Nuss SL, Wilson ME. Health-related quality of life following hematopoietic stem cell transplant during childhood. Journal of Pediatric Oncology Nursing. 2007;24(2):106-115. https://doi.org/10.1177/1043454206296033

20. Clarke SA, Skinner R, Guest J, Darbyshire P, Cooper J, Vora A, et al. Clinical outcomes and health-related quality of life (HRQOL) 
following hematopoietic stem cell transplantation (HSCT) for pediatric leukemia. Child. 2011;37(4):571-580.

https://doi.org/10.1111/j.1365-2214.2010.01182.x

21. Park MN. Descriptive study on self-identity, resilience and health related quality of life in adolescent survivors with cancer [master's thesis]. Seoul: Yonsei University; 2016. p. 1-95.

22. Michel G, Bordigoni P, Simeoni MC, Curtillet C, Hoxha S, Robitail $S$, et al. Health status and quality of life in long-term survivors of childhood leukemia: The impact of hematopoietic stem cell transplantation. Bone Marrow Transplantation. 2007;40(9):897-904. https://doi.org/10.1038/sj.bmt.1705821

23. Kim YJ, Kwon HJ. The experiences of adolescents' suffering from cancer: Breaking out of the withdrawn Ego. Asian Oncology Nursing. 2013;13(4):304-312.

https://doi.org/10.5388/aon.2013.13.4.304

24. Shin HG. Influencing factors of quality of life, self-esteem of higher grade primary school children. Journal of the Korean Data Analysis Society. 2015;17(1):485-499.

25. Oh SM, Lee HJ, Kim GS, Part KD. Factors affecting social adjust- ment of childhood cancer survivors. Child Health Nursing Research. 2013;19(3):238-245.

https://doi.org/10.4094/chnr.2013.19.3.238

26. Son SY. Illness experience of adolescents with hematologic malignancies. Journal of Korean Academy of Nursing. 2011;41(5):603-612. https://doi.org/10.4040/jkan.2011.41.5.603

27. Finnegan L, Campbell RT, Ferrans CE, Wilbur JE, Wilkie DJ, Shaver J. Symptom cluster experience profiles in adult survivors of childhood cancers. Journal of Pain and Symptom Management. 2009;38(2):258-269.

https://doi.org/10.1016/j.jpainsymman.2008.09.010

28. Ritchie MA. Self-esteem and hopefulness in adolescents with cancer. Journal of Pediatric Nursing. 2001;16(1):35-42. https://doi.org/10.1053/jpdn.2001.20551

29. Haase JE, Kintner EK, Monahan PO, Robb SL. The resilience in illness model. Part 1: Exploratory evaluation in adolescents and young adults with cancer. Cancer Nursing. 2014;37(3):E1-E12. https://doi.org/10.1097/NCC.0b013e31828941bb 